\title{
Developmental Depression of Glutamate Neurotransmission by Chronic Low-Level Activation of NMDA Receptors
}

\author{
Jian Shi, ${ }^{1}$ Sandra M. Aamodt, ${ }^{2}$ Matthew Townsend, ${ }^{1,3}$ and Martha Constantine-Paton ${ }^{1}$ \\ ${ }^{1}$ Departments of Biology and Brain and Cognitive Science and The McGovern Brain Research Institute, Massachusetts \\ Institute of Technology, Cambridge, Massachusetts 02139, and 2Department of Biology and 3/nterdepartmental \\ Neuroscience Program, Yale University, New Haven, Connecticut 06520
}

\begin{abstract}
Slabs of slow-release plastic (Elvax) containing NMDA or solvent were implanted over the rat colliculus beginning on postnatal day 8 (P8). Whole-cell patch clamping in the superficial superior collicular layers (sSCs) from P10 to P21 demonstrated a severe decrease in spontaneous EPSC frequency after chronic NMDA treatment. The decrease was not attributable to an increase in $\mathrm{GABA}_{\mathrm{A}}$ receptor-mediated inhibition and was present only when NMDA receptor (NMDAR) current was blocked by $\mathrm{Mg}^{2+}$. Analysis of miniature EPSCs indicated that many active sites on NMDA-treated neurons lacked functional AMPA and kainate receptor (AMPA/KAR) currents, and AMPA/ KAR:NMDAR current ratios of evoked EPSCs were also significantly reduced. In addition, the normal downregulation of NMDAR decay time in SSC neurons at P11 was absent after NMDA treatment. Nevertheless, neither AMPA nor NMDA receptor subunit expression was altered by NMDA treatment, and experiments with the NMDAR antagonist ifenprodil suggested
\end{abstract}

that incorporation of NR2A-containing NMDARs at the SSC synapses was unperturbed. Thus, disrupting but not blocking NMDARs suppresses the development of AMPA/KAR currents. The absence of the P11 NMDAR current downregulation is likely a secondary effect resulting from the reduction of AMPA/ KAR function. Chronic agonist application reduces but does not eliminate NMDAR conductances. Therefore these data support an active role for NMDAR currents in synaptic development. Prolonged NMDA treatment in vivo, which couples reduced postsynaptic $\mathrm{Ca}^{2+}$ responses with normally developing afferent activity, produces a long-lasting synaptic depression and stalls glutamatergic synaptogenesis, suggesting that the correlation between robust NMDAR activation and afferent activity is an essential component during normal development.

Key words: NMDA receptors; AMPA receptors; development; synaptic competition; correlation detection; long-term depression; whole-cell patch clamping; superior colliculus
Most models of activity-dependent synaptogenesis link activity to selective reinforcement of synapses via a competitive process (Wiesel and Hubel, 1965). In the CNS, synapses that produce brief, large influxes of $\mathrm{Ca}^{2+}$ are reinforced (Constantine-Paton and Cline, 1998). However, inputs associated with slow, small influxes of $\mathrm{Ca}^{2+}$ are suppressed and ultimately lost (Artola et al., 1990; Brocher et al., 1992; Kandler et al., 1998; Dodt et al., 1999; Yang et al., 1999). Direct evidence for such correlation detection in synaptic competition is strongest for developing neuromuscular synapses. Calcium influx through nicotinic cholinergic receptors selectively weakens less active inputs (Dan and Poo, 1992), and reducing nicotinic cholinergic receptor function in vivo produces a physical withdrawal selective to terminals presynaptic to the relatively ineffectual postsynaptic membranes (Balice-Gordon and Lichtman, 1994). Studies of multiply innervated junctions developing in vivo also indicate that functional weakening of inputs precedes physical synapse elimination (Colman et al., 1997).

Young CNS synapses are potentiated in tissue slices by activation of presynaptic inputs in rapid succession or by pairing postsynaptic depolarization with minimal presynaptic stimula-

\footnotetext{
Received Feb. 14, 2001; revised May 10, 2001; accepted May 24, 2001.

This work was supported by National Institutes of Health Grants NS-32290 to M.C.-P., MH-11535 to S.M.A., and 5T32DA07290 and 5T32EY07115 to M.T.

Correspondence should be addressed to Martha Constantine-Paton, Departments of Biology and Brain and Cognitive Science, Massachusetts Institute of Technology, 77 Massachusetts Avenue, Building 68-380, Cambridge, MA 02139. E-mail: mcpaton@mit.edu.

Copyright (C) 2001 Society for Neuroscience $\quad 0270-6474 / 01 / 216233-12 \$ 15.00 / 0$
}

tion. This potentiation requires functional NMDA receptors (NMDARs; Bear et al., 1992; Zhang et al., 1998) and is most pronounced when structural synaptic plasticity is robust (Crair and Malenka, 1995; Fox, 1995; Kirkwood et al., 1995; Isaac et al., 1997). Conversely, the strength of developing synapses is depressed by weak synaptic activation (Dudek and Bear, 1992; Kirkwood and Bear, 1994) or by presynaptic activation that occurs while the postsynaptic membrane voltage is clamped at a level allowing only small amounts of NMDAR current (Feldman et al., 1998). Like potentiation, depression in slices coincides developmentally with periods of peak structural plasticity in intact tissue (Dudek and Friedlander, 1996; Feldman et al., 1999).

Do the same mechanisms underlie this functional plasticity and structural plasticity during development in the intact brain? Experiments using chronic NMDAR blockade in vivo suggest that, indeed, NMDARs modulate sprouting between competing inputs (Cline et al., 1987; Kleinschmidt et al., 1987; Rabacchi et al., 1992; Simon et al., 1992; Schnupp et al., 1995; Colonnese and Constantine-Paton, 2001). However, eliminating receptor function does not address the issue of correlation detection and functional synaptic competition (Stent, 1973). We have therefore taken another approach.

NMDA was infused into the colliculus beginning at postnatal day 8 (P8), when robust spontaneous synaptic currents are present, afferent stimulation evokes large EPSCs (Shi et al., 1997), but light-driven activity is not yet detectable (Fortin et al., 1999). We have previously shown that this same chronic NMDA treatment does not cause neuron loss in the superficial visual 
collicular layers (Aamodt et al., 2000). We now demonstrate, using whole-cell patch-clamp recordings from treated superficial superior collicular layer (sSC) neurons, that this chronic NMDA exposure produces a highly significant reduction in AMPA and kainate receptor (AMPA/KAR) activity at both afferent-driven and interneuronal sSC synapses. These data support the role of the NMDAR as a correlation detector during synaptogenesis by showing that glutamatergic synaptic maturation shows a longlasting depression when in vivo NMDAR activation is not large or tightly associated with afferent activation.

\section{MATERIALS AND METHODS}

Animals and surgery. Sprague Dawley female rats were purchased from Camm and Charles River (Wilmington, MA), and their litters were used for all experiments. The day of birth was counted as postnatal day 0 . At P8, a $180-\mu \mathrm{m}$-thick slice of the ethylene-vinyl acetate copolymer Elvax (DuPont, Billerica, MA) was surgically implanted over the superficial layers of the superior colliculus, as described previously (Simon et al., 1992). Anesthesia was induced with a halothane vaporizer, and a small incision was made over the sagittal sinus to allow insertion of the Elvax. The incision was closed with sutures and Vetbond (3M, Minneapolis, $\mathrm{MN})$. Antibiotic ointment was applied, and pups were returned to the mother after they recovered from anesthesia. The Elvax contained a concentration of $100 \mu \mathrm{M}$ NMDA in $20 \mu \mathrm{l}$ of water (NMDA treatment). This was estimated to release molecules of the size of NMDA in the range of hundreds of nanomoles per day (Cline and Constantine-Paton, 1989, 1990; Simon et al., 1992; Smith et al., 1995). Sham Elvax contained an equivalent volume $(20 \mu \mathrm{l})$ of water.

Electrophysiology. Pups, ages P10-P20, were anesthetized with isoflurane and killed by decapitation. The diencephalon and midbrain were placed in cold artificial CSF (ACSF) containing (in mM): $117 \mathrm{NaCl}, 3$ $\mathrm{MgCl}_{2}, 4 \mathrm{KCl}, 3 \mathrm{CaCl}_{2}, 1.2 \mathrm{NaHPO}_{4}, 26 \mathrm{NaHCO}_{3}$, and 16 glucose, saturated with $95 \% \mathrm{O}_{2}$ and $5 \% \mathrm{CO}_{2}$ to a final $\mathrm{pH}$ of 7.4. Recordings were made from 300-400 $\mu \mathrm{m}$ parasagittal slices of the midbrain maintained at room temperature $\left(22-24^{\circ} \mathrm{C}\right)$ and perfused with ACSF at $4 \mathrm{ml} / \mathrm{min}$. At least $2 \mathrm{hr}$ elapsed between cutting and recording from the slices. Recording procedures have been presented previously (Shi et al., 1997). Borosilicate glass patch electrodes (World Precision Instruments) with tip resistances of 5-10 $\mathrm{M} \Omega$ were filled with (in $\mathrm{mM}$ ): $122.5 \mathrm{Cs}$-gluconate, 17.5 CsCl, 10 HEPES (CsOH), 0.2 Na-EGTA, 2 MgATP, 0.3 NaGTP, and 8 $\mathrm{NaCl}$. In most experiments, $0.2 \%$ biocytin, $\mathrm{pH} 7.3$, was added to the electrode to allow subsequent visualization of cell types. Most sSC neuron types were recorded from in this study, and the anatomical results have been reported previously (Aamodt et al., 2000). Recorded voltages were adjusted for a liquid junction potential offset of $10 \mathrm{mV}$. Cells had resting potentials between -45 and $-58 \mathrm{mV}$.

Whole-cell recordings were restricted to neurons in the stratum griseum superficiale or stratum zonale. All cells studied had seal resistances of $2-2.5 \mathrm{G} \Omega$ and series resistances of $<21 \mathrm{M} \Omega$. We rarely attempted to study spontaneous events in more than two neurons per collicular slice in treated animals. Each cell was usually held for 1-2 hr for recording of glutamatergic current frequencies, reported here, and $\mathrm{GABA}_{\mathrm{A}}$ receptor currents, reported previously (Aamodt et al., 2000). Glutamatergic current kinetics were analyzed in separate experiments. Events were considered synaptic currents if they had rise times of $\geq 8-9$ msec with amplitudes measured from the noise midline that were at least two times one-half peak-to-peak baseline noise. We analyzed only recordings in which the series resistance and input impedance did not change $>10 \%$ over the course of the experiment. Signals were recorded using an Axoclamp ID patch-clamp amplifier, filtered at $5 \mathrm{kHz}$, and interfaced (CED 1401 Plus, Cambridge Electronic Design, Cambridge, England) with a Pentium-based computer (Gateway 2000) that stored the data and provided on-line response display and off-line data analysis. CED patchand voltage-clamp software was used to acquire and analyze data.

Most of this analysis focused on spontaneous EPSCs (sEPSCs) of cells held at $-60 \mathrm{mV}$. The use of spontaneous currents eliminated complications produced by changes in the effectiveness of evoked synaptic activation that occur over the P10-P20 interval, probably as a result of myelination and presynaptic maturation of collicular inputs. Spontaneous current frequencies were measured with $3 \mathrm{~mm} \mathrm{Mg}^{2+}$ in the ACSF. Frequencies of EPSCs for each cell were obtained by selecting intervals of at least $70 \mathrm{sec}$ (between 300 and 1000 events) starting 2-3 min after setting the holding potential and at least $5 \mathrm{~min}$ after a solution change.
We counted all single fast currents meeting our criteria of synaptic currents within that interval. When multiple events were superimposed, later events were counted only when they occurred after the previous current had returned to $<20 \%$ of peak value. This criterion was chosen for consistency with previous data analyses (Shi et al., 1997; Aamodt et al., 2000).

Analyses of excitatory current amplitude, frequency, and kinetics used miniature EPSCs (mEPSCs) recorded in $0 \mathrm{mM} \mathrm{Mg}^{2+}$ containing $0.2 \mu \mathrm{M}$ tetrodotoxin (TTX) and $2 \mu \mathrm{M}$ bicuculline methiodide (BMI). The criteria for selecting events and analyzing frequency were the same as those for spontaneous events. Currents from each neuron were averaged using customized software written by J.S. Analysis of the peak amplitude of mEPSCs recorded in neurons of all ages and all treatment groups showed no consistent changes in these parameters (see Fig. 3). Thus, for comparisons of decay kinetics across ages and treatments, it was possible to estimate average mEPSC decay time for each neuron $\left(\bar{D}_{m}\right)$ using the average mEPSC of the cell and the single exponential tau estimator: the time from peak to 0.37 peak amplitude. Averages were generally derived from at least 40 single events. For each neuron, mEPSCs were averaged before and again after the addition of either $50 \mu \mathrm{M}$ 2-amino-5phosphonopentanoic acid (AP-5) or $5 \mu \mathrm{M}$ ifenprodil. An estimate of NMDAR current decay for each neuron was obtained by subtracting the average mEPSC decay with AP-5 from $\overline{\mathrm{D}}_{\mathrm{m}}$. The contribution to synaptic decay of receptors containing only NR1 and NR2B subunits was estimated using ifenprodil, which selectively blocks these receptors at low concentrations (Williams et al., 1993; Ramoa and Prusky, 1997). In preliminary experiments, effects on mEPSC current were obtained with $3 \mu \mathrm{M}$ ifenprodil. However, $5 \mu \mathrm{M}$ ifenprodil was routinely applied because it required less time to produce the same stable change in current decay. To effectively display the effect induced by ifenprodil, the average difference in mEPSC decay attributable to ifenprodil for each neuron $\left(\overline{\mathrm{D}}_{\mathrm{m}}-\overline{\mathrm{D}}_{\mathrm{mw} / \mathrm{Ifen}}\right)$ was expressed as a proportion of $\overline{\mathrm{D}}_{\mathrm{m}}$ for that neuron. This value factors out the contribution of ifenprodil-independent current decay changes and represents the percent contribution of NR1- and NR2B-containing receptors to the synaptic current decay.

Electrical stimuli were delivered to the stratum opticum through bipolar electrodes composed of a pair of tungsten or platinum iridium microelectrodes with a tip separation of $\sim 50 \mu \mathrm{m}$. To enable qualitative comparisons of current amplitude across neurons, stimulation intensity was adjusted for each neuron to lie approximately midway between the minimal current that would evoke a response at $-70 \mathrm{mV}$ in $\mathrm{Mg}^{2+}$ containing ACSF and the stimulus intensity at which the evoked current saturated. Stimuli consisted of $6-10 \mu \mathrm{A}$ pulses of $0.5 \mathrm{msec}$ duration delivered at $0.1 \mathrm{~Hz}$. All evoked currents were recorded between P11 and P14 to minimize changes in effectiveness produced by development of afferents, NMDA current regulation, and inhibition. Currents were recorded in ACSF containing $2 \mathrm{~mm} \mathrm{Mg}^{2+}$ and $6 \mu \mathrm{M}$ BMI. The AMPA/ KAR contribution to the evoked EPSCs was determined at $-70 \mathrm{mV}$ in the presence of $100 \mu \mathrm{M}$ AP-5, and the NMDAR contribution to these EPSCs was determined at $+40 \mathrm{mV}$ in the presence of $15 \mu \mathrm{M}$ GYKI 52466. At least nine evoked currents at each holding potential were averaged for each neuron, and the average amplitude was used to determine AMPA receptor (AMPAR):NMDAR ratios.

Molecular analyses. For biochemical experiments, rats were killed by carbon dioxide followed by cervical dislocation, and the superficial layers of the superior colliculus were rapidly dissected. AMPAR subunits were analyzed in synaptoneurosome fractions using previously published techniques (Hollingsworth et al., 1985; Scheetz et al., 2000). For these experiments, normal and sham- and NMDA-treated animals from 2 separate litters were killed on P12. Tissue was homogenized in ice-cold oxygenated buffer (in mM: $118 \mathrm{NaCl}, 4.7 \mathrm{KCl}, 1.2 \mathrm{MgSO}_{4}, 2.5 \mathrm{CaCl}_{2}, 1.53$ $\mathrm{KH}_{2} \mathrm{PO}_{4}$, and 212.7 glucose) containing complete protease inhibitor (Roche Molecular Biochemicals, Indianapolis, IN). The homogenate was passed through a series of nylon filters of descending pore size [final pass through an MLCWP 047 filter (Millipore, Bedford, MA) with a $10 \mu \mathrm{m}$ pore size] and centrifuged for $15 \mathrm{~min}$ at $1000 \times g$. The pellet was resuspended in Laemmli buffer and frozen in aliquots at $-80^{\circ} \mathrm{C}$. Aliquots were heated to $90^{\circ} \mathrm{C}$ for $5 \mathrm{~min}$ before loading on gels.

NMDAR subunit levels were analyzed in membrane fractions from P19 rats to facilitate comparisons with our previous work (Shi et al., 1997, 2000) and to maximize treatment time. For these experiments, thawed homogenate was centrifuged for $10 \mathrm{~min}$ at $4^{\circ} \mathrm{C}$ at $16,000 \times g$. The pellet was resuspended in one-fourth volume of $2 \mathrm{~mm}$ HEPES, pH 7. 2, and centrifuged for $10 \mathrm{~min}$ at $4^{\circ} \mathrm{C}$ at $11,000 \times g$. The second pellet was resuspended in $0.5 \mathrm{~mm}$ HEPES, $\mathrm{pH} 7.3$, containing $0.32 \mathrm{~m}$ sucrose and 
centrifuged for $8 \mathrm{~min}$ at $450 \times g$. The supernatant from this spin (a membrane fraction) was placed in Laemmli buffer, heated to $90^{\circ} \mathrm{C}$ for 5 min, and frozen in aliquots at $-80^{\circ} \mathrm{C}$.

Immunoblotting of proteins used primary antibodies to AMPAR subunits (GluR1, 0.5 $\mu \mathrm{g} / \mathrm{ml}$; and GluR2, $0.5 \mu \mathrm{g} / \mathrm{ml}$; Chemicon, Temecula, CA; and GluR4, $1 \mu \mathrm{g} / \mathrm{ml}$; Upstate Biotechnology, Lake Placid, NY) and NMDAR subunits (NR1, $0.5 \mu \mathrm{g} / \mathrm{ml}$; NR2A, 1:400; and NR2B, 1:600; Chemicon). $\alpha$-Actin visualized with antibody AC-40 (1:100; Sigma, St. Louis, MO) served as a loading control for the AMPAR subunits. Data for AMPAR and NMDAR subunits in sham- and NMDA-treated animals were normalized to untreated collicular tissue of the same age run on the same gels. Electrophoresis used 6 or $8 \%$ polyacrylamide minigels with proteins loaded at 5 or $10 \mu \mathrm{g} /$ lane. Proteins were transferred to nitrocellulose by electroblotting (Idea Scientific). Total protein was visualized with Ponceau 5 stain. Blots were blocked with $1 \%$ dried milk in $0.1 \%$ Tween and $0.1 \mathrm{M}$ PBS (TPBS) for $30 \mathrm{~min}$ and then incubated in primary antibody in TPBS for $1 \mathrm{hr}$ at room temperature. After four 10 min rinses in milk and TPBS, blots were incubated in secondary antibody (horseradish peroxidase-conjugated goat anti-rabbit, 1:10,000 for the AMPAR subunits and 1:12,000 for the NMDAR subunits; or goat anti-mouse, 1:10,000 for the AMPAR subunits and 1:2000 for the NMDAR subunits). Blots were washed six times for 5 min each in TPBS and then reacted with chemiluminescent substrate (Pierce, Rockford, IL) and exposed to film (Eastman Kodak, Rochester, NY). At least two protein isolations were used for the analysis of each set of subunits.

Tissue for transcript analysis of the NMDAR subunits was homogenized directly from the freezer in 25 volumes of buffer ( $4 \mathrm{M}$ guanidinium, $17 \mathrm{~mm} N$-lauroylsarcosine, $100 \mathrm{~mm}$ Tris, $5 \mathrm{~mm}$ Na-citrate, and $100 \mathrm{~mm}$ 2-mercaptoethanol), and RNA was extracted and precipitated according to previously described procedures (Shi et al., 1997). The RNA levels of the three NMDA receptor subunits (NR1, NR2A, and NR2B) in a single sample, along with a probe for $28 \mathrm{~S}$ transfer RNA (115 bp; Ambion, Austin, TX) as a loading control were quantified using a ribonuclease protection assay. The NR1 probe protects a 180-bp fragment between positions 421 and 600 . The NR2A probe protects a 369-bp fragment from 2993 to 3362 . The NR2B probe protects a 262-bp fragment from 4019 to 4280. All probes were synthesized by in vitro transcription with $\left[{ }^{32} \mathrm{P}\right]$ UTP. The specific activity of the NR1 probe was 16 -fold lower than that of the NR2 subunit probes to equalize exposure times. The protection assay was run with the RPA II kit (Ambion), using $10 \mu \mathrm{g}$ of total RNA, 20,000 cpm of each NMDA receptor subunit probe, $1000 \mathrm{cpm}$ of the $28 \mathrm{~S}$ probe, and $1 \mu \mathrm{g}$ of the cold $28 \mathrm{~S}$ probe. All probes were determined to be in at least fourfold molar excess over the sample RNA. In each run, separate control lanes for each probe with $10 \mu \mathrm{g}$ of yeast RNA gave no signal. Gels were dried and exposed to x-ray film at $-80^{\circ} \mathrm{C}$ for 4-8 d. Each film contained lanes for each age, and densitometric values from each film were normalized to the value for the adult lane to facilitate comparison across films with different exposure times.

Band density on the autoradiographs was measured by densitometry with NIH Image 1.57 and its gel-plotting macros. Pixel intensities were calibrated to optical densities with a density wedge. A dilution series processed with the samples confirmed that measurements were within the linear range of the film. All data are reported as mean $\pm \mathrm{SE}$ of band optical densities.

\section{RESULTS}

Developmental changes in excitatory and inhibitory synapses are unusually synchronized across the diverse population of neurons within the superficial layers of the rat sSC. In a previous wholecell patch-clamp study, we recorded a few neurons in the first postnatal week that completely lacked AMPA/KAR-mediated mEPSCs. However, after this brief period, all untreated neurons had mEPSCs composed of AMPA/KAR and NMDAR currents, with no consistent change in the relative proportions of the two currents across the rest of synaptic development (Shi et al., 2000). We have also shown that the frequency of sEPSCs in the sSC, a measure of intracollicular circuitry, increases gradually until P16 or P17. At this age, a rapid decrease in excitatory event frequency and an increase in the amplitude of $\mathrm{GABA}_{\mathrm{A}}$ receptor-mediated currents occur simultaneously (Shi et al., 1997; Aamodt et al., 2000). Finally, the NMDAR undergoes a rapid, activity- and calcineurin-mediated downregulation of its decay time between P10 and P11. The latter is superimposed on a slower incorporation of NMDARs with faster kinetics, those containing the NR2A subunit (Shi et al., 2000). In the present study, similar whole-cell patch-clamp analyses showed a pronounced change in all but one of these developmental patterns after chronic exposure to NMDA from P8.

\section{Spontaneous EPSC frequency}

Cells from NMDA-treated animals, held near their resting potential in $2 \mathrm{~mm} \mathrm{Mg}^{2+}$, showed significantly less spontaneous activity (Fig. 1) than cells from sham-treated littermates from P10 through P16. However, after P16 or P17, when sham-treated, like untreated, sSC neurons (Shi et al., 1997) show a significant drop in sEPSC frequency, there was no difference in sEPSC frequency between NMDA- and sham-treated neurons (Fig. 1A,B). The same NMDA treatment of the sSC from $\mathrm{P} 8$ causes a premature increase in $\mathrm{GABA}_{\mathrm{A}}$ receptor-mediated currents (Aamodt et al., 2000). This raised the possibility that the treatment-induced depression in spontaneous sEPSC activity might be attributable to an increase in inhibitory currents. Consequently, slices were treated with $2 \mu \mathrm{M} \mathrm{GABA}_{\mathrm{A}}$ receptor antagonist BMI to directly examine the role of inhibition in NMDA- and sham-treated neurons (Fig. 1C). Sham-treated neurons showed the BMIinduced increase in frequency during the third postnatal week seen previously in untreated neurons (Shi et al., 1997). However, $\mathrm{GABA}_{\mathrm{A}}$ receptor blockade did not alter sEPSC frequency in any of the NMDA-treated neurons studied. These observations demonstrate that the suppression in sEPSC frequency after NMDA treatment is not attributable to $\mathrm{GABA}_{\mathrm{A}}$ receptor-mediated inhibition.

In contrast to the responses in magnesium-containing ACSF, when NMDA-treated slices were bathed in magnesium-free ACSF, most neurons showed an unusually rapid increase in spontaneous activity that led to paroxysmal depolarization and seizure-like activity. Paroxymal depolarizations and seizure activity were never observed in untreated sSC neuropils of the same age after similar short exposures to magnesium-free ACSF (Shi et al., 1997). Data from NMDA- and sham-treated neurons after exposure to $0 \mathrm{~mm} \mathrm{Mg}^{2+}$ were excluded from further analyses because of the likelihood of excitotoxic damage and biased sampling.

\section{Miniature EPSCs}

To reduce the excitability of the tissue while studying glutamate currents in the absence of inhibition, we added TTX to the bath and examined mEPSCs in magnesium-free ACSF with BMI. Analyses of current kinetics were conducted at $-60 \mathrm{mV}$ near the resting potentials of the cells, because in the sSC (Hestrin, 1992), as in several other regions of the brain (Konnerth et al., 1990; D'Angelo et al., 1994), the kinetics of NMDAR currents show a pronounced voltage dependence. Currents are faster near the resting potential of the cells and slow considerably with depolarization and repolarization.

A decrease in spontaneous EPSC frequency after NMDA treatment combined with hyperexcitability of the same tissue in $\mathrm{Mg}^{2+}$-free ACSF suggested that a large proportion of active sites on sSC neurons might lack functional AMPA/KAR currents as a result of the treatment. Analyses of mEPSCs confirmed this possibility and suggested that the lack of AMPA/KAR expression secondarily affected the normal downregulation of NMDAR current. 
A
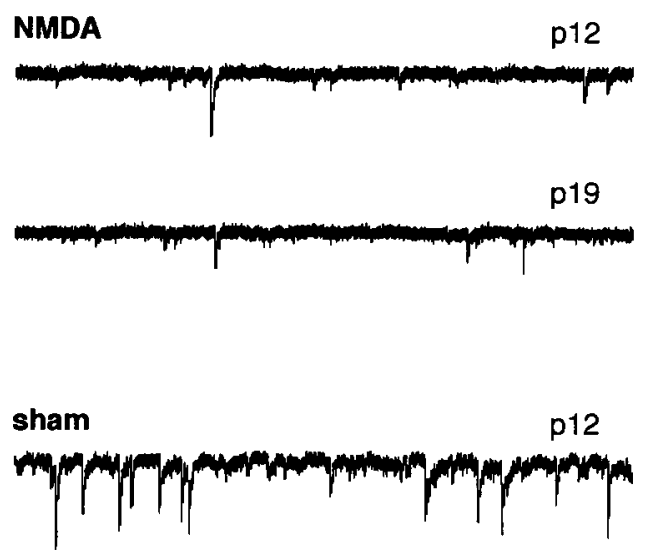

p19

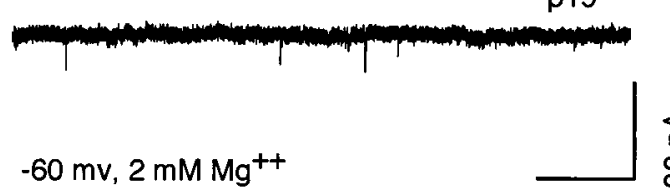

1 sec.
B

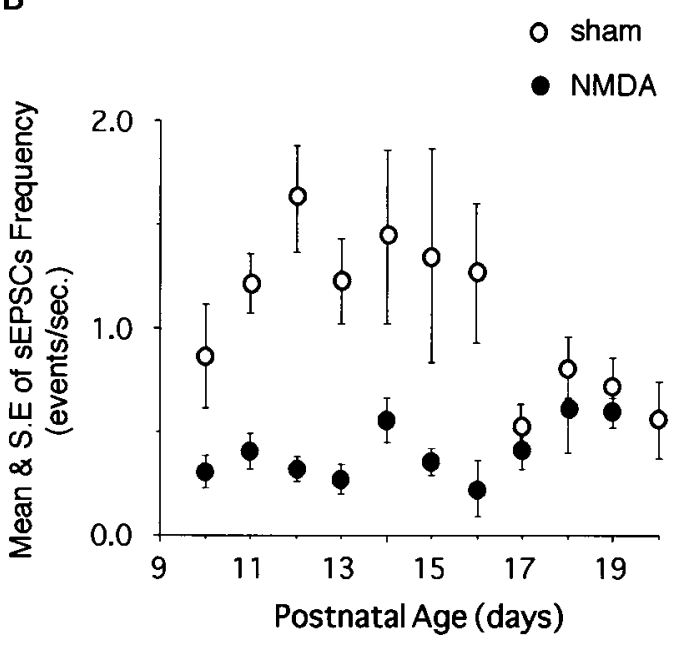

$\mathrm{C}$

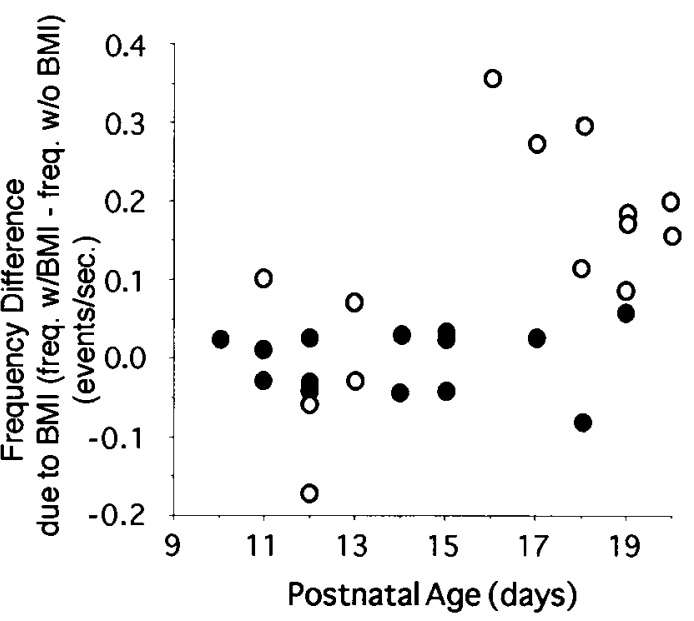

Figure 1. NMDA-treated neurons show reduced levels of spontaneous activity compared with sham-treated neurons before the onset of inhibition at $\sim$ P17. $A$, Traces from P12 and P19 neurons in NMDA- and sham-treated sSCs. $B$, The frequency of spontaneous EPSC activity in NMDA-treated sSC neurons $(n=78)$ held at $-60 \mathrm{mV}$ is significantly decreased (Student's $t$ test, $p \ll 0.0001)$ in $2 \mathrm{mM} \mathrm{Mg}^{2+}$ relative to sham-treated sSC neurons $(n=$ 68). The mean \pm SE of sEPSC frequency for neurons recorded on each postnatal day is plotted against postnatal age. $C$, BMI does not increase the frequency of sEPSCs in NMDA-treated neurons, but BMI does increase the sEPSC frequency in sham-treated neurons, as in untreated neurons, beginning on P16 ( $n=19$ sham-treated neurons and 13 NMDA-treated neurons).

Decay times of mEPSCs are determined by NMDAR current decay, because NMDAR kinetics are considerably slower than those of AMPA/KARs. In our previous studies, the abrupt P10-P11 decrease in NMDAR current decay time was observed in both spontaneous EPSCs (Shi et al., 1997) and miniature EPSCs (Shi et al., 2000) at all synapses of all normal rat sSC neurons we studied. In contrast to normal or sham-treated neurons, however, long, AP-5-sensitive mEPSCs were still present in neurons from NMDA-treated colliculi even at the oldest ages tested (Fig. $2 A-C$ ), indicating that the P10-P11 developmental decrease in NMDAR current decay time had not occurred. In addition, mEPSCs from $\sim 20 \%$ of the NMDA-treated neurons (eight cells) showed a pronounced effect on AMPA/KAR currents. When these cells were exposed to AP-5, all mEPSCs (above the criterion of two times baseline) were eliminated from the recordings (Fig. 2D). Neurons lacking AMPA/KAR mEPSCs were only encountered in slices $<13 \mathrm{~d}$ old, before eye opening and the onset of pattern vision (see Fig. $4 A$ ).

Peak amplitudes, NMDAR current decay times, and average
mEPSC frequencies were estimated from the mEPSC recording from each neuron, as described in Materials and Methods. The average $\mathrm{mEPSC}$ frequencies with and without AP-5 were determined for most cells. For these analyses, we excluded all NMDAtreated neurons showing no AMPA/KAR-mediated mEPSCs.

No consistent differences were found in mEPSC amplitude across treatment groups (Fig. 3A; ANOVA, $p>0.05$ ) or NMDAR contribution to amplitude across treatment groups (Fig. $3 B$ ) when the contribution of NMDAR currents was examined as the difference between peak amplitude in the absence and presence of AP-5 (Fig. 3B; ANOVA, $p=0.3 ; n=29$ NMDA-treated neurons, 25 sham-treated neurons, and 18 untreated neurons). Thus the number of NMDARs at active sites did not change appreciably with NMDA treatment. In addition, there were no significant differences among the three treatment groups in mEPSC frequency (Fig. 4A; ANOVA, $p>0.05$ ) suggesting that NMDA treatment did not significantly alter the number of synaptic contacts. However, decreases in mEPSC frequency in the presence of AP-5 (Fig. 4B,C) were greater in NMDA-treated 
A

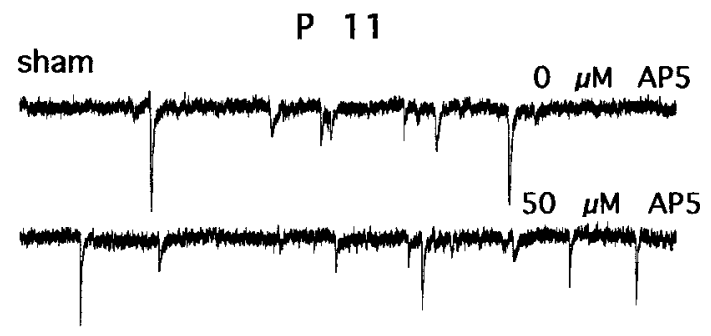

B
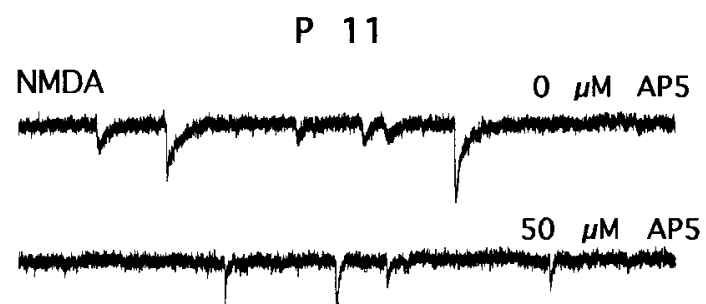

C

P 19

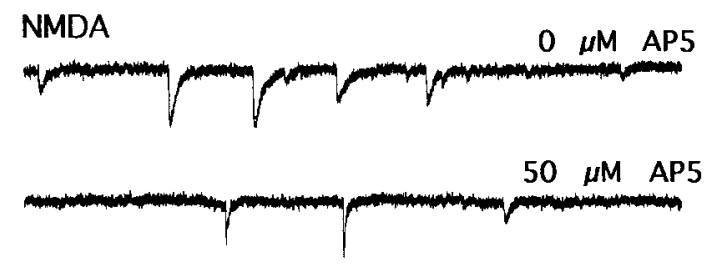

D

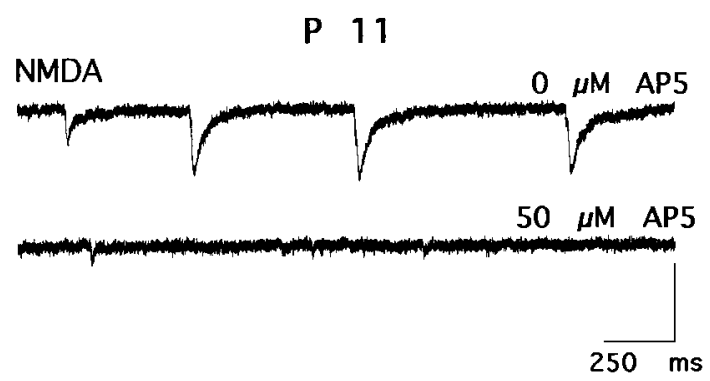

Figure 2. Recordings of mEPSCs in magnesium-free ACSF show effects of NMDA treatment on NMDAR current decay and on the prevalence of AMPA/KAR-mediated responses. $A$, Representative traces of mEPSCs recorded in a P11 sham-treated SSC neuron with and without AP-5 show that in sham-treated as in untreated neurons, the NMDAR current makes only a small contribution to mEPSC decay at this age. $B$, Neurons of the same age from NMDA-treated sSCs, however, show a prolonged mEPSC decay that is caused by NMDAR currents with long decay times, as indicated by the pronounced shortening of the current during AP-5 exposure. This effect of NMDAR blockade is characteristic of sham-treated and untreated neurons before a calcineurin-mediated decrease in NMDAR decay time that occurs between P10 and P11 (Shi et al., 2000). C, Prolonged mEPSC decay times caused by NMDAR currents with slow kinetics are still prevalent in neurons from sSC slices taken late in the third postnatal week, as indicated in traces from a P19 NMDA-treated neuron. $D$, Some neurons from NMDA-treated slices have pure NMDAR-mediated mEPSCs, as indicated by the absence of all mEPSCs when $50 \mu \mathrm{M}$ AP- 5 is present.
A

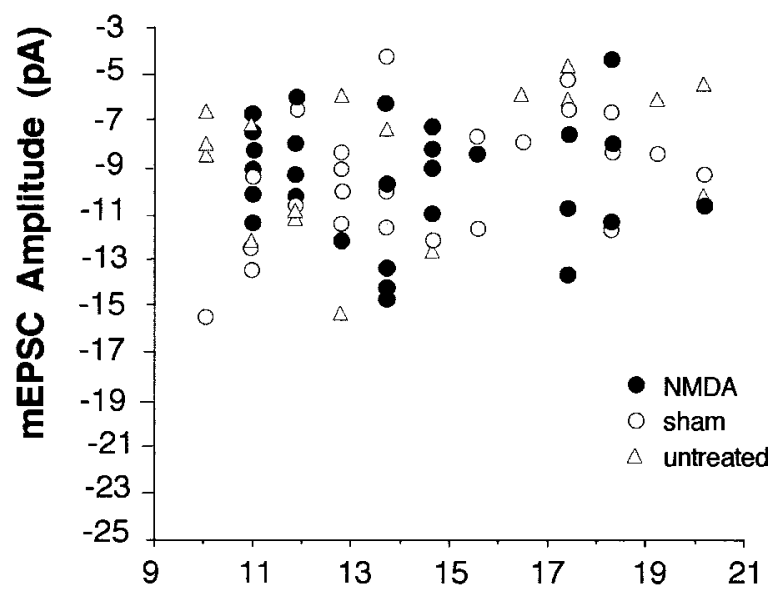

B

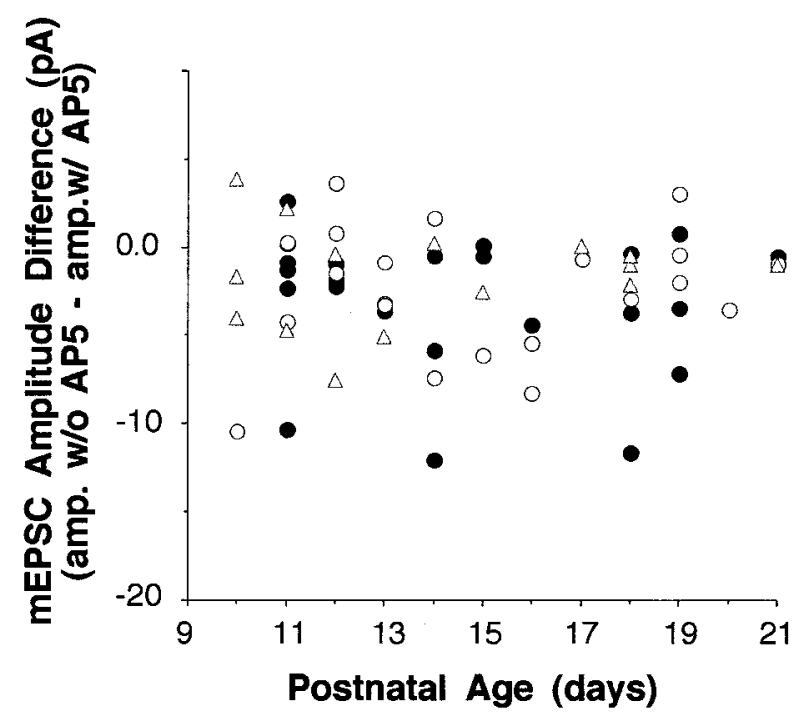

Figure 3. Effects of acute NMDAR blockade on mEPSCs recorded in magnesium-free ACSF indicate little change in the NMDA contribution to the peak amplitude of the mEPSCs. $A$, Scatter plot showing no consistent change in average mEPSC amplitude across the P10-P20 interval and no difference in average mEPSC amplitude between untreated and NMDA- and sham-treated neurons. $B$, Scatter plot of the difference between average mEPSC amplitude for each neuron in the absence versus the presence of AP-5 for NMDA- and sham-treated and untreated SSC neurons. The data show no consistent differences across postnatal age or across treatments (ANOVA, $p=0.31 ; n=29$ NMDAtreated neurons, 25 sham-treated neurons, and 18 untreated neurons). All recordings were made at $-60 \mathrm{mV}$ in $0 \mathrm{~mm} \mathrm{Mg} \mathrm{Mg}^{2+}$.

neurons than in either sham-treated or untreated neurons (Fig. $4 C$; ANOVA, $p=0.0001$, Tukey's post hoc NMDA vs sham; NMDA vs untreated, $p=0.001$; sham vs untreated, $p=0.8 ; n=$ 22 NMDA-treated neurons, 25 sham-treated neurons, and 15 untreated neurons). Because these observations derive from miniature EPSCs rather than action potential-mediated events, they reflect function at single active sites. Thus decreased mEPSC frequency with acute NMDAR blockade after chronic NMDA treatment indicates that the treatment reduces the number of active sites showing significant functional expression of AMPA/ KARs. Taken together with the observations that the NMDAR contribution to miniature EPSCs does not change and that 8 of the 37 NMDA-treated neurons studied showed no mEPSCs in the presence of AP-5, these data suggest a pronounced and 


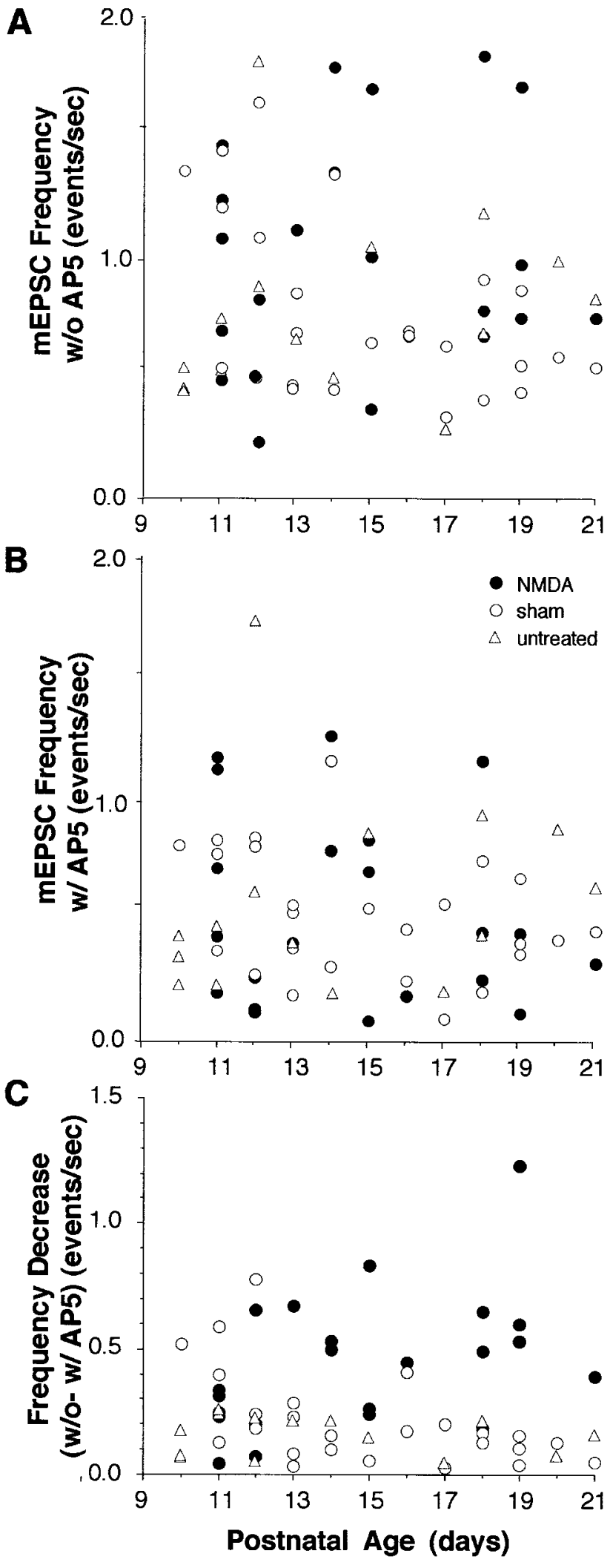

Figure 4. Effects of acute NMDAR blockade on mEPSCs recorded in magnesium-free ACSF indicate a significant increase in the number of active sites showing only NMDAR currents after NMDA treatment. $A$, Scatter plot showing the range of mEPSC frequencies in different neurons. There were no significant differences among the treatment groups (ANOVA, $p>0.05$ ), suggesting no consistent change in the total number of active sites on SSC neurons with chronic NMDA treatment. $B$, mEPSC relatively selective effect on the maturation of AMPA/KAR current amplitude by chronic NMDA treatment.

Although an increase in the magnitude of AMPA/KAR currents is one hallmark of glutamate synaptic maturation, one of the most pronounced effects of maturation on NMDAR current is in the downregulation of its decay time. Therefore, to determine whether NMDAR maturation was also affected by NMDA treatment begun at P8, we quantitatively examined the decay kinetics of the average mEPSCs (Fig. 5). There were no significant differences in NMDAR current decay between sham-treated and untreated neurons (Tukey's post hoc test, $p \leq 0.0001$ after the ANOVA below). Consequently, these cells are grouped in the scatter plot of Figure $5 A$. The untreated and sham-treated neurons showed the typical P10-P11 drop in NMDAR decay time (Shi et al., 1997, 2000). Rapidly decaying NMDAR currents were not present in most NMDA-treated neurons (Fig. $5 A$ ). Comparison of the average NMDAR decay time revealed a significant difference between the NMDA-treated groups with and without AMPA/KAR-mediated currents (Student's $t$ test, $p=0.001$; Fig. $5 A, B)$. This may indicate that neurons lacking AMPA/KAR currents in their mEPSCs are also retarded in the insertion of NR2A subunits into their synaptic NMDARs. Insertion of the NR2A subunit is likely to be responsible for early decreases in NMDA decay time in the colliculus (Shi et al., 2000), and data from the visual cortex suggests that retardation of activity decreases NR2A incorporation into functional NMDARs (Nase et al., 1999). Because of the significant difference between data from the two NMDA-treated neuron groups, we treated this analysis conservatively, and the large NMDAR decay time estimates from the "pure NMDAR" neurons were not included in subsequent comparisons of NMDAR decay kinetics across treatments. Nevertheless, the analysis still revealed highly significant differences among NMDA- and sham-treated or untreated neurons (ANOVA, $p<0.0001$; Tukey's post hoc test, NMDA vs sham, $p=$ 0.0001 ; NMDA vs untreated, $p=0.001$; Fig. $5 B$ ). In short, these analyses of mEPSCs reveal different effects on AMPAR/KARs and NMDARs resulting from chronic NMDA exposure. Both effects reflect a suppression of the normal maturation pattern of the receptor type. AMPA/KAR currents generally increase with age in the sSC neuropil (Shi et al., 2000), and this is stalled or depressed with the treatment. The NMDAR current amplitude is normally stable over this postnatal period, but the NMDAR current decay time shows a rapid downregulation (Shi et al., 1997). The NMDAR current amplitude does not appear to be affected by chronic NMDA treatment, but the treatment abolishes the rapid P10-P11 decrease in the NMDAR decay time. Maintenance of normal NMDAR numbers at synapses and absence of the decay time decrease likely contribute to the hyperexcitability of NMDA-treated sSCs in $0 \mathrm{~mm} \mathrm{Mg}^{2+}$.

frequencies in the same neurons as in $A$ after addition of AP-5 to the bathing medium. $C$, The difference between average mEPSC frequency for the sSC neurons shown in $A$ and $B$ in the absence versus the presence of AP-5. The data indicate relatively small effects of acute NMDAR blockade on mEPSC frequencies in sham-treated and untreated neurons. However, significantly larger decreases in frequency with AP-5 are present in NMDA-treated neurons (ANOVA, $p=0.0001$; Tukey's post hoc NMDA vs sham and NMDA vs untreated, $p=0.001$; sham vs untreated, $p=0.8$; $n=22$ NMDA-treated neurons, 25 sham-treated neurons, and 15 untreated neurons). All recordings were made at $-60 \mathrm{mV}$ in $0 \mathrm{mM} \mathrm{Mg} \mathrm{Mg}^{2+}$. 


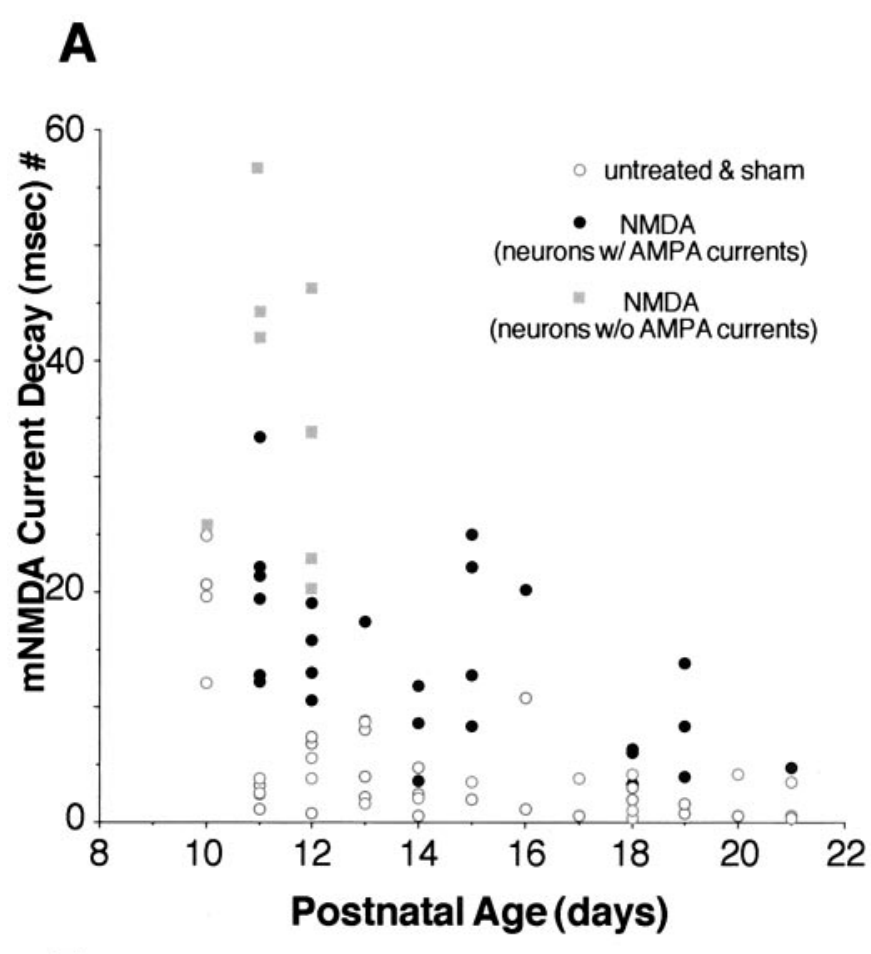

B

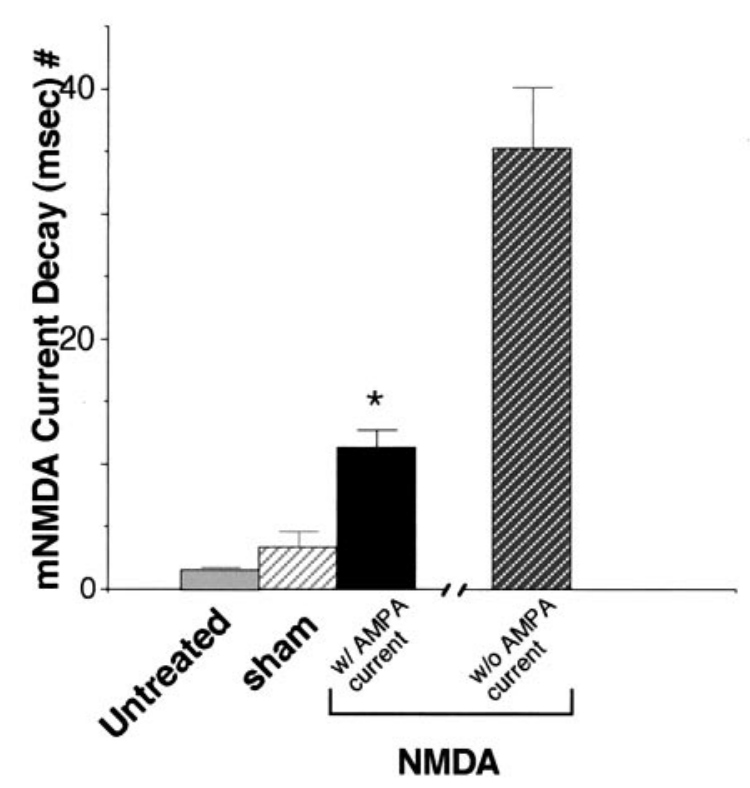

Figure 5. Summary of mEPSC analyses showing NMDAR current downregulation during the $\mathrm{P} 10-\mathrm{P} 21$ interval in untreated and shamtreated SSCs and its absence in NMDA-treated SSC. $A$, The NMDAR current decay times were estimates (\#) based on the difference in decay time of the average mEPSC for each neuron with AP-5 and the decay time of the average mEPSC for the same neuron without AP-5. Such estimates of NMDAR current decay times from untreated and sham-treated neurons were not significantly different and are therefore grouped together. The untreated and sham-treated neurons show the rapid NMDAR current downregulation previously demonstrated to be attributable to calcineurin (Shi et al., 2000). Most NMDA-treated neurons do not show the P10-P11 decrease in NMDAR decay time. NMDA-treated neurons lacking AMPA/KAR mEPSCs are plotted on the same axes for comparison and show decay times that are significantly longer than NMDA-treated neurons with AMPA/KAR mEPSCs (Student's $t$ test, $p=0.001$ ). Neurons lacking AMPA/KAR mEPSCs were not encountered in recordings after P12. B, Histograms showing the average estimated NMDAR decay

\section{AMPA/KAR:NMDAR current ratios of SSC evoked currents}

Slice recordings of mEPSCs could reflect activity at synapses normally driven by the retina, the cortex, or neurons within the slice itself. We asked whether the pronounced loss of AMPA/ KAR activity evident in the mEPSCs from NMDA-treated neurons was also evident when collicular neurons were driven by their afferent inputs. Submaximal electrical stimuli were delivered to afferents in the stratum opticum while whole-cell currents were recorded in ACSF containing $2 \mathrm{mM} \mathrm{Mg}^{2+}$ supplemented with antagonists that isolated the AMPA/KAR current at -70 $\mathrm{mV}$ and the NMDAR current at $+40 \mathrm{mV}$ (see Materials and Methods). Peak NMDAR and AMPA/KAR current amplitudes were measured from averages of the NMDAR and AMPAR EPSCs for each neuron. Absolute evoked AMPA/KAR and NMDAR current amplitudes could not be quantitatively compared across cells, because different numbers of inputs were probably activated in different neurons as a result of unavoidable variations in stimulating electrode placement relative to the total population of innervating axons of the cells (see Materials and Methods). Nevertheless, as illustrated in Figure 6A, the AMPA/ KAR evoked currents in NMDA-treated neurons appeared to be significantly reduced in size compared with the same currents in either sham-treated or untreated neurons, whereas the NMDAR evoked currents in the same three groups of neurons showed relatively less variation. Thus average AMPA/KAR currents in sham and untreated sSC neurons were $83.9 \pm 14.0$ (SEM) versus $88.6 \pm 4 \mathrm{pA}$, whereas in NMDA treated neurons the average AMPA/KAR current was $45.3 \pm 5.8 \mathrm{pA}$. The average NMDA currents across the same three groups of neurons were sham, $48.9 \pm 8.9$; untreated, $48.6 \pm 2.2$; and NMDA, $66.1 \pm 7.2 \mathrm{pA}$. When the AMPA/KAR:NMDAR current ratio was calculated for each neuron, however, the reduction of the ratio in NMDAtreated neurons was highly significant (Fig. 6B; ANOVA, $p \ll$ 0.001; Tukey's post hoc test, NMDA vs sham and NMDA vs untreated $p=0.0001$; sham vs untreated, $p=0.9 ; n=13$ NMDA-treated neurons, 7 sham-treated neurons, and 13 untreated neurons; all between P11 and P14).

\section{Receptor subunit expression after NMDA treatment}

To determine whether the decrease in AMPA/KAR currents reflected a decrease in AMPA protein expression, quantitative Western blot analysis was performed on P12 synaptoneurosome protein from normal and sham- and NMDA-treated colliculi. This age was selected to correspond to the period of large physiologically detected differences in the AMPA/KAR currents between sham- and NMDA-treated neurons. Tissue from NMDA- and sham-treated and untreatred animals was run on the same gels, transferred, and blotted with antibodies to the AMPA receptor subunits GluR1, GluR4, GluR2, and $\alpha$-actin. The shamand NMDA-treated lanes were normalized to the untreated tissue run on the same gels. Students' $t$ tests between the two treatments groups revealed no differences (data not shown; $p>$

time for each of the treatment groups. NMDA-treated neurons with AMPA/KAR mEPSCs, sham-treated neurons, and untreated neurons are significantly different (ANOVA, $p<0.0001$ ). Tukey's post hoc tests showed no difference between sham-treated and untreated neurons ( $p=$ $0.6)$ and significant differences $(*)$ between NMDA- and sham-treated neurons $(p=0.0001)$ and between NMDA-treated and untreated neurons $(p=0.001 ; n=29$ NMDA-treated neurons, 25 sham-treated neurons, and 18 untreated neurons). 
A
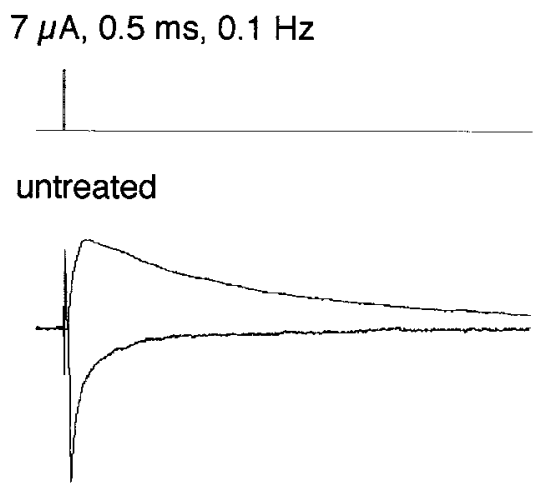

sham

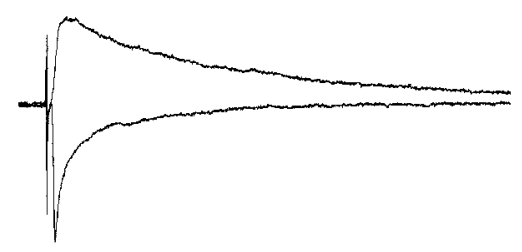

NMDA

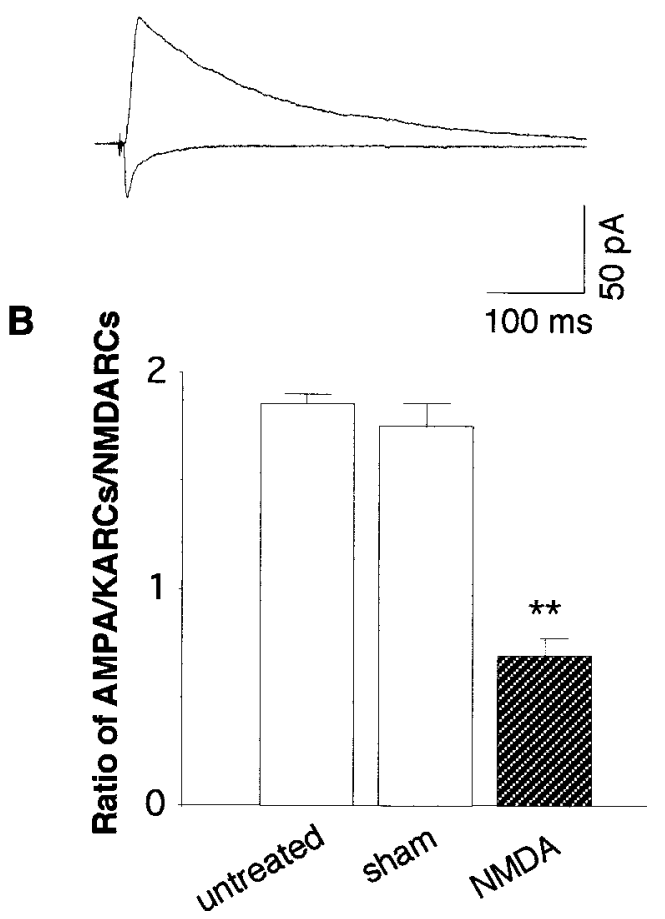

Figure 6. AMPA/KAR:NMDAR current ratios derived from evoked currents are reduced in neurons from NMDA-treated tissue relative to neurons from sham-treated or untreated tissue. $A$, Average currents evoked by electrical stimulation of the stratum opticum (inset) were studied at $+40 \mathrm{mV}$ in $\mathrm{Mg}^{2+}$-containing ACSF with GYKI 52466 and BMI added to isolate the NMDAR-mediated component and at $-70 \mathrm{mV}$ with AP-5 and BMI to isolate the AMPA/KAR-mediated component. Traces from a P13 untreated and a P13 sham-treated neuron illustrate the relatively larger peak amplitude of the AMPA/KAR current in collicular neurons in the P11-P14 age range. Traces from the P13 NMDA-treated neuron illustrate the decrease in the AMPA/KAR-mediated component relative to the NMDAR-mediated component after agonist treatment. $B$, Quantitative comparison of the AMPA/KAR:NMDAR current ratios from 13 untreated neurons, 7 sham-treated neurons, and 13 NMDA-
$0.05 ; n=2$ protein isolations and 5 gels). Nevertheless, the effects of NMDA treatment on the NMDAR subunits could be quite different from the effects of the treatment on AMPARs. At least one component of the activity-dependent change in the decay time of developing NMDARs involves alterations in the expression of NR2A subunits (Monyer et al., 1994; Flint et al., 1997; Stocca and Vicini, 1998; Nase et al., 1999; Quinlan et al., 1999). Furthermore, neurons in culture show increased expression of NR2B transcript under conditions of decreased activation (Audinat et al., 1994; Follesa and Ticku, 1996). To determine whether the slowing of the NMDAR decay time after chronic NMDA treatment might be attributable to decreased expression of the NR2A subunit or increased expression of the NR2B subunit, or whether the NMDAR transcript levels responded to this treatment as if activity were decreased by the treatment in vivo, we took tissue at P19 after $11 \mathrm{~d}$ of NMDA exposure. At this age, differences between NMDAR current decays in sham- and NMDA-treated neurons were still apparent, but expression of NR2A was significantly increased in untreated animals (Shi et al., 1997, 2000). We performed RNase protection assays and quantitative Western blotting on untreated and NMDA- and shamtreated sSCs for each of the three dominant NMDAR subunits in the colliculus. As in the AMPAR analysis, levels of subunit transcript and protein were normalized to data from untreated colliculi run on the same gels. The only molecular difference in any NMDAR subunit observed between NMDA- and shamtreated SSCs was an increase in the NR2B subunit mRNA transcript. However, at the protein level, the NR2B subunit did not reflect the transcript change (Fig. $7 A$ ).

We also applied the atypical NMDAR antagonist ifenprodil at low concentrations to NMDA- and sham-treated neurons after recording mEPSCs in $0 \mathrm{~mm} \mathrm{Mg}^{2+}$ without any antagonists present. At low concentrations, ifenprodil blocks synaptic current carried by receptors containing only the NR1 and NR2B subunits (Williams et al., 1993; Ramoa and Prusky, 1997). We estimated the proportion of synaptic current decay contributed by NR1/ $N R 2 B$ receptors by calculating the proportion $\overline{\mathrm{D}}_{\mathrm{m}}-\overline{\mathrm{D}}_{\mathrm{mw} / \mathrm{Ifen}} / \overline{\mathrm{D}}_{\mathrm{m}}$ for each neuron (see Materials and Methods). In untreated rats during the P10-P21 period, this proportion shows a relatively linear slow decline (Shi et al., 2000). Because the amplitude of NMDAR synaptic current shows no consistent change over this period in any treatment group or across treatments (Shi et al., 2000, their Fig. 3), the contribution of NR1 and NR2B receptors to current decay should represent the inverse of the current carried by NR2A-containing receptors. Thus, if incorporation of NR2A into synaptic receptors were slowed by NMDA treatment, the percentage of current decay carried by NR1 and NR2B receptors should be increased in NMDA-treated relative to sham-treated or untreated neurons. Comparison of NMDA- and sham-treated cells from the present study with untreated cells of the same ages (Fig. $7 B$ ) from our previous work showed no significant differences in the NR1 and NR2B contribution to the synaptic current among these groups (ANOVA, $p>0.05 ; n=18$ NMDA-treated neurons, 13 sham-treated neurons, and 15 untreated neurons from Shi et al., 2000).

\section{$\longleftarrow$}

treated neurons between P11 and P14. Differences between NMDAtreated neurons and both untreated and sham-treated neurons are highly significant (**; ANOVA, $p \gg 0.0001$; Tukey's post hoc NMDA vs untreated, $p>0.0001$; NMDA vs sham, $p>0.0001$; sham vs untreated, $p=0.7)$. 
A

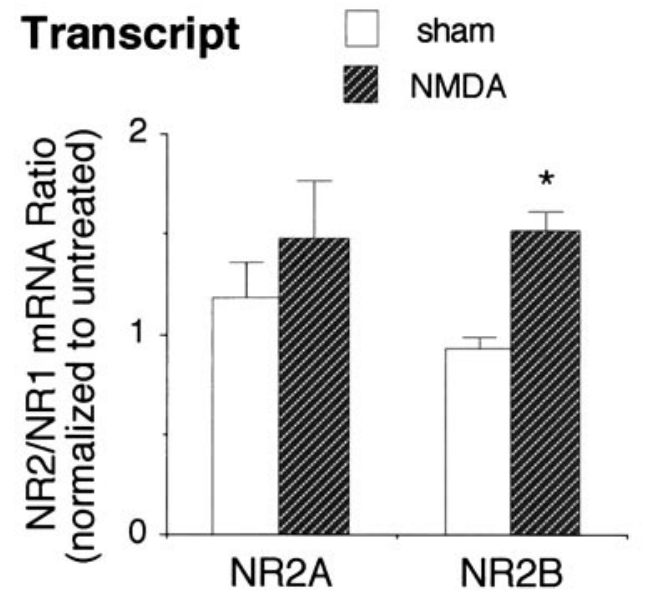

\section{Protein}

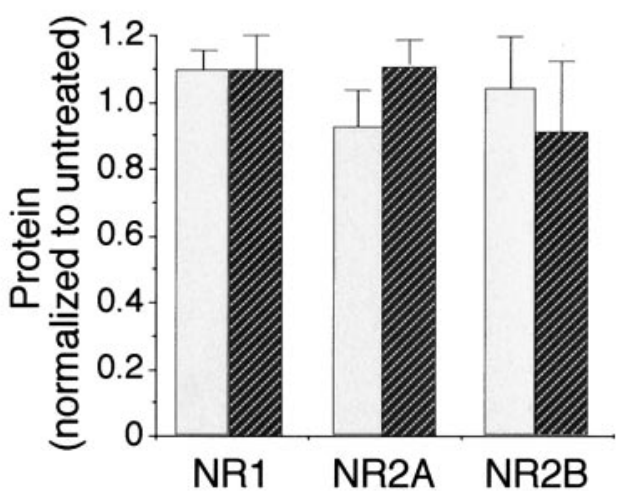

Figure 7. Neither the expression of NMDAR subunits nor their incorporation into functional synaptic receptors changes in sSC neurons after NMDA treatment. $A$, Quantitative ribonuclease protection assays for the NR1, NR2A, and NR2B subunits show no changes in the level of NR2A transcript between sham- and NMDA-treated tissue. However, the NR2B transcript was significantly elevated (*; Students' $t$ test, $p<$ $0.01 ; n=2$ RNA isolations and 4 gels). As a loading control, the transcript data are expressed as the ratio of the NR1 level in the same lanes. Western blot data from membrane fractions of $\mathrm{sSC}$ using antibodies to NR1, NR2A, and NR2B show no differences in the levels of any of the subunits between shamand NMDA-treated colliculi ( $n=3$ protein isolations and 8-10 blots). All data are normalized to results for untreated rats of the same age on the same film. $B$, Analyses of changes in mEPSC decay time in $0 \mathrm{mM} \mathrm{Mg}^{2+}$ with and without ifenprodil estimate the contribution of NMDARs containing only NR1 and NR2B subunits to mEPSC decay. The percentage of contribution is given as the difference between the average decay time of the mEPSCs without ifenprodil $\left(\bar{D}_{m}\right)$ and the average decay time with ifenprodil $\left(\bar{D}_{m \text { w/Ifen }}\right)$ divided by the average decay time without ifenprodil for the same neuron. This percentage did not differ among sham-treated, untreated, and NMDA-treated neurons (ANOVA, $p=0.06 ; n=18$ NMDAtreated neurons, 13 sham-treated neurons, and 15 untreated neurons), suggesting that chronic NMDA exposure does not significantly affect the amount of the NR2A subunit incorporated into synaptic NMDARs in the sSC. Note, however, that NMDA-treated neurons lacking AMPA/KAR current miniature EPSCs and with unusually long decay times were not found during the ifenprodil experiments, and their data,

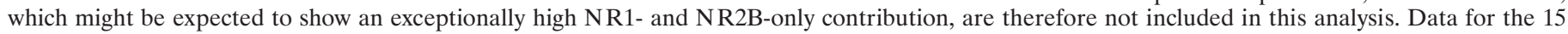
untreated neurons are from Shi et al. (2000).

\section{DISCUSSION}

In the superficial visual layers of the superior colliculus, synaptogenesis can be studied anatomically (Thong and Dreher, 1986; Warton and McCart, 1989; Contamina and Boada, 1992; Simon and O'Leary, 1992; Simon et al., 1992; Colonnese and Constantine-Paton, 2001) and physiologically (Itaya et al., 1995; Binns and Salt, 1997; Fortin et al., 1999) because of the direct and dominant innervation from the retina and visual cortex and the synchronization of synaptic development (Shi et al., 1997, 2000; Aamodt et al., 2000). Previously we reported that chronic application of low levels of NMDA to the sSC at P8 upregulates $\mathrm{GABA}_{\mathrm{A}}$ receptor-mediated synaptic activity at P12, $5 \mathrm{~d}$ before this increase would occur during normal development. The increase is not attributable to changes in neuron number or the proportion of GABAergic neurons (Aamodt et al., 2000). In this report, we show an opposite effect of the same treatment on glutamatergic synaptic maturation; that is, chronic NMDA exposure retards the development of glutamate synapses. The conclu- sion is based on four findings. First, spontaneous activity is significantly depressed in all NMDA-treated compared with sham-treated neurons in normal ACSF. Second, this depression is independent of changes in GABAergic neurotransmission, because blockade of the $\mathrm{GABA}_{\mathrm{A}}$ receptor in NMDA-treated $\mathrm{SSC}$ fails to increase spontaneous EPSC frequency, and decreased glutamatergic current frequencies are present in our youngest recordings on $\mathrm{P} 10$, before the appearance of enhanced $\mathrm{GABA}_{\mathrm{A}}$ receptor-mediated currents. Third, after NMDA treatment, many synaptic active sites do not show age-appropriate AMPA/ $\mathrm{KAR}$ responses. These responses are reduced in mEPSCs and at afferent synapses, as reflected in the AMPA/KAR:NMDAR current ratios of evoked EPSCs. This decrease in AMPA/KAR currents is the most likely cause of the depressed synaptic activity in NMDA-treated tissue, because the suppression is not observed when $\mathrm{Mg}^{2+}$ is removed from the bath. Fourth, the activityinduced downregulation of the NMDAR decay time that nor- 
mally occurs between P10 and P11 (Shi et al., 2000) is not observed in NMDA-treated tissue, suggesting that activity in the intact animal during chronic NMDA exposure, and not just in the isolated slice, is reduced by this treatment. The increased expression of transcript for the NR2B subunit in NMDA-treated colliculi is also consistent with depressed activity in vivo, because activity blockade of cultured neurons produces the same selective increase in the transcript for this subunit (Audinat et al., 1994; Follesa and Ticku, 1996).

The finding that NMDA treatment has opposite effects on GABAergic and glutamatergic transmission is not unexpected in light of studies showing differences in glutamate receptor populations and types of plastic responses at synapses onto inhibitory versus excitatory neurons (Laezza et al., 1999; McBain et al., 1999). Opposite responses of GABA and glutamate receptormediated synaptic transmission after chronic depolarization also occur in tissue culture (Turrigiano et al., 1998). The latter studies are similar to ours in that $\mathrm{GABA}_{\mathrm{A}}$ receptor-mediated transmission is augmented, whereas glutamatergic transmission is depressed. However, these observations are on cortical neurons, for which both in vivo (Marty et al., 1997; Rutherford et al., 1998) and in vitro (Rutherford et al., 1997) data suggest that the GABAergic changes are driven by BDNF released by excitatory neurons on activation. In the NMDA-treated sSC, however, it is very unlikely that excitatory activity leads to increased BNDF secretion, given the present data indicating decreased, rather than increased, excitation under conditions in which GABAergic currents become more pronounced. Instead we favor an effect on the GABA synthetic enzyme glutamate decarboxylase, on the $\mathrm{GABA}_{\mathrm{A}}$ receptor itself, or on GABA neuron excitability as possible explanations for the increases in GABergic transmission in the sSC. This effect on GABA function could be a strictly trophic response to tonic low levels of $\mathrm{Ca}^{2+}$ influx through NMDARs and need not imply that glutamatergic synapses onto inhibitory and excitatory neurons are affected differently by chronic NMDA exposure.

The present results are similar to findings in earlier experiments on plasticity indicating that acute NMDA application either before or after tetanic activation can prevent induction of long-term potentiation (Coan et al., 1989; Izumi et al., 1992). Application of $20 \mu \mathrm{M}$ NMDA to hippocampal slices for 3 min will produce long-term depression (LTD; Lee et al., 1998). In these experiments, as in ours, it is likely that the agonist treatment desensitizes NMDARs (Sather et al., 1992), thus reducing the ability of active inputs to produce large postsynaptic $\mathrm{Ca}^{2+}$ currents. Afferent activity associated with small or prolonged NMDAR currents is expected to produce synaptic depression (Yang et al., 1999). Indeed, a transient, long-duration $\mathrm{Ca}^{2+}$ current has been implicated in normal collicular LTD during early postnatal life (Lo and Mize, 2000). A similar long-term depression attributable to coupling of afferent activation with abnormally low postsynaptic $\mathrm{Ca}^{2+}$ currents could explain a surprising result of monocular deprivation. In kittens, the open eye shows reduced thalmocortical terminal arborization (Hata et al., 1999) and reduced synaptic effectiveness (Reiter and Stryker, 1988) relative to the deprived eye when cortical neuron excitability is depressed by chronic muscimol treatment. The present results are also consistent with the observation that many excitatory synapses are silent in young tissue (Isaac et al., 1995, 1997; Durand et al., 1996; Liao and Malinow, 1996; Wu et al., 1996; Rumpel et al., 1998; Baba et al., 2000). Such results have led to the suggestion that NMDARs are the earliest ionotropic receptors to appear at young glutamatergic synapses, and that the pattern of NMDAR activation actively modulates the appearance of AMPA/KAR currents at the same contacts. Whether this effect is attributable to postsynaptic insertion of AMPA receptors or presynaptic modulation of glutamate release kinetics is still controversial (Kullmann and Asztely, 1998; Renger et al., 2001). However, regardless of presynaptic or postsynaptic locus, the greater reduction in mEPSC frequency after NMDA receptor blockade in NMDA-treated cells relative to sham-treated and untreated cells and the reduced AMPA/KAR:NMDAR EPSC ratios after NMDA treatment attributable primarily to a decreased evoked AMPA/KAR current amplitude indicate that early chronic NMDA treatment greatly reduces the number of AMPARs involved in synaptic transmission throughout the sSC.

The present findings also demonstrate a cascade of events that can result from distorting the relationship between NMDAR responsiveness and endogenous synaptic function in vivo. In our experiments, reduced AMPA/KAR currents suppress excitatory neurotransmission, but these synapses would probably show enhanced potentiation if the NMDAR could function (Dudek and Bear, 1993). The reduction of normal activity is the likely cause of the lack of the normal NMDAR current downregulation between P10 and P11 in the sSC. The latter is attributable to the NMDAR-dependent activation of the $\mathrm{Ca}^{2+} /$ calmodulindependent kinase calcineurin and can be induced by stimulation of collicular afferents in vitro (Shi et al., 2000). Thus, if the NMDAR $\mathrm{Mg}^{2+}$ block is removed, both increased NMDAR effectiveness and increased potential for synaptic potentiation favor the hyperexcitability that we observe in NMDA-treated tissue. NMDAR downregulation through incorporation of NR2A-containing synaptic receptors (Monyer et al., 1994; Flint et al., 1997; Stocca and Vicini, 1998) has also been reported to have an activity-dependent component (Nase et al., 1999; Quinlan et al., 1999). Our data suggest that NR2A incorporation may be retarded in some NMDA-treated neurons before eye opening (Fig. 5), but this effect appears to be transient or restricted to a small subset of cells, or both.

In summary, early weak activation of NMDARs appears to stall glutamatergic differentiation, even though, or perhaps because, normal afferent innervation remains intact. This may reflect events likely to occur during normal development of excitatory synapses in vivo. At early stages, glutamate uptake systems are immature, yet growth cones release glutamate (LoT urco et al., 1991), and young synapses have a high probability of release (Bolshakov and Siegelbaum, 1995; Pouzat and Hestrin, 1997). Under such conditions, both AMPA and NMDA receptors probably exist in a relatively desensitized state (Sather et al., 1992), and only rapid-onset volleys of highly correlated synaptic events produce the large pulses of intracellular free $\mathrm{Ca}^{2+}$ necessary for synaptic reinforcement. Instead, the activity of most inputs is correlated with slow-onset, small changes in postsynaptic free $\mathrm{Ca}^{2+}$; AMPAR function is depressed; and only subsequent robust driving of inputs produces potentiation and begins synapse stabilization. If synaptic depression predicts physical synapse loss, then these conditions in early neuropils should favor synaptic turnover, known to occur in the early colliculus (Simon and O'Leary, 1992). These interactions would increase the fidelity of synaptic refinement by assuring that only the most highly effective inputs are stabilized. This scenario also suggests that any number of disruptions associated with mutations, infection, or trauma, such as abnormal positioning of neurons, timing of afferent invasion, or high extracellular glutamate, could alter which synapses 
become reinforced, leading indirectly to permanent circuit dysfunction and neurological or cognitive disease. However, neural development also appears buttressed against such events. The absence of the activity-induced, calcineurin-dependent downregulation of the NMDAR current would help counter effects of NMDAR desensitization, and the acceleration of inhibitory GABAergic maturation in the sSC neuropil (Aamodt et al., 2000) constitutes an adaptive response to hyperexcitability.

\section{REFERENCES}

Aamodt SM, Shi J, Colonnese MT, Veras W, Constantine-Paton M (2000) Chronic NMDA exposure accelerates development of GABAergic inhibition in the superior colliculus. J Neurophysiol 83:1580-1591.

Artola A, Brocher S, Singer W (1990) Different voltage-dependent thresholds for inducing long-term depression and long-term potentiation in slices of rat visual cortex. Nature 347:69-72.

Audinat E, Lambolez B, Rossier J, Crepel F (1994) Activity-dependent regulation of $N$-methyl-D-aspartate receptor subunit expression in rat cerebellar granule cells. Eur J Neurosci 6:1792-1800.

Baba H, Doubell TP, Moore KA, Woolf CJ (2000) Silent NMDA receptor-mediated synapses are developmentally regulated in the dorsal horn of the rat spinal cord. J Neurophysiol 83:955-962.

Balice-Gordon RJ, Lichtman JW (1994) Long-term synapse loss induced by focal blockade of postsynaptic receptors. Nature 372:519-524.

Bear MF, Press WA, Connors BW (1992) Long-term potentiation in slices of kitten visual cortex and the effects of NMDA receptor blockade. J Neurophysiol 67:1-11.

Binns KE, Salt TE (1997) Post eye-opening maturation of visual receptive field diameters in the superior colliculus of normal and dark-reared rats. Brain Res 99:263-266.

Bolshakov VY, Siegelbaum SA (1995) Regulation of hippocampal transmitter release during development and long-term potentiation. Science 269:1730-1734.

Brocher S, Artola A, Singer W (1992) Intracellular injection of $\mathrm{Ca}^{2+}$ chelators blocks induction of long-term depression in rat visual cortex. Proc Natl Acad Sci USA 89:123-127.

Cline HT, Constantine-Paton M (1989) NMDA receptor antagonists disrupt the retinotectal topographic map. Neuron 3:413-426.

Cline HT, Constantine-Paton M (1990) NMDA receptor agonist and antagonists alter retinal ganglion cell arbor structure in the developing frog retinotectal projection. J Neurosci 10:1197-1216.

Cline HT, Debski E, Constantine-Paton M (1987) NMDA receptor antagonist desegregates eye specific strips. Proc Natl Acad Sci USA 84:4342-4345.

Coan EJ, Irving AJ, Collingridge GL (1989) Low frequency activation of the NMDA receptor system can prevent the induction of LTP. Neurosci Lett 105:205-210.

Colman H, Nabekura J, Lichtman JW (1997) Alterations in synaptic strength preceding axon withdrawal. Science 275:356-361.

Colonnese MT, Constantine-Paton M (2001) Chronic NMDA receptor blockade from birth increases the sprouting capacity of ipsilateral retinocollicular axons without disrupting their early segregation. J Neurosci 21:1557-1568.

Constantine-Paton M, Cline HT (1998) LTP and activity-dependent synaptogenesis: the more alike they are, the more different they become. Curr Opin Neurobiol 8:139-148.

Contamina P, Boada E (1992) Time of origin of cortico-collicular projection neurons in the rat visual cortex. J Comp Neurol 323:570-576.

Crair MS, Malenka RC (1995) A critical period for long-term potentiation at thalamocortical synapses. Nature 375:325-328.

Dan Y, Poo M (1992) Hebbian depression of isolated neuromuscular synapses in vitro. Science 256:1570-1573.

D'Ángelo E, Rossi P, Taglietti V (1994) Voltage-dependent kinetics of $\mathrm{N}$-methyl-D-aspartate synaptic currents in rat cerebellar granule cells. Eur J Neurosci 6:640-645.

Dodt H-U, Eder M, Frick A, Zieglgansberger W (1999) Precisely localized LTD in the neocortex revealed by infrared-guided laser stimulation. Science 286:110-113.

Dudek SM, Bear MF (1992) Homosynaptic long-term depression in area CA1 of hippocampus and the effects of NMDA receptor blockade. Proc Natl Acad Sci USA 89:4363-4367.

Dudek SM, Bear MF (1993) Bidirectional long-term modification of synaptic effectiveness in the adult and immature hippocampus. J Neurosci 13:2910-2918.

Dudek SM, Friedlander MJ (1996) Developmental downregulation of LTD in cortical layer IV and its independence of modulation by inhibition. Neuron 16:1097-1106.

Durand GM, Kovalchuk Y, Konnerth A (1996) Long-term potentiation and functional synapse induction in developing hippocampus. Nature 381:71-75.
Feldman DE, Nicoll RA, Malenka RC, Issac JTR (1998) Long-term depression at thalamocortical synapses in developing rat somatosensory cortex. Neuron 21:347-357.

Feldman DE, Nicoll RA, Malenka RC (1999) Synaptic plasticity at thalamocortical synapses in developing rat somatosensory cortex: LTP, LTD, and silent synapses. J Neurobiol 41:92-101.

Flint AC, Maisch US, Weishaupt JH, Kriegstein AR, Monyer H (1997) NR2A subunit expression shortens NMDA synaptic currents in developing neocortex. J Neurosci 17:2469-2476.

Follesa P, Ticku MK (1996) NMDA receptor upregulation: molecular studies in cultured mouse cortical neurons after chronic agonist exposure. J Neurosci 16:2172-2178.

Fortin S, Chabli A, Dumont I, Shumikhina S, Itaya SK, Molotchnikoff S (1999) Maturation of visual receptive field properties in the rat superior colliculus. Dev Brain Res 112:55-64.

Fox K (1995) The critical period for long-term potentiation in primary sensory cortex. Neuron 15:485-488.

Hata Y, Tsumoto T, Stryker MP (1999) Selective pruning of more active afferents when cat visual cortex is pharmacologically inhibited. Neuron 22:375-381.

Hestrin S (1992) Developmental regulation of NMDA receptormediated synaptic currents at a central synapse. Nature 357:686-689.

Hollingsworth EB, McNeal ET, Burton JL, Williams RJ, Daly JW, Creveling CR (1985) Biochemical characterizations of a filtered synaptoneuronsome preparation from guinea pig cerebral cortex: cyclic adenosine $3^{\prime}: 5^{\prime}$-monophosphate-generating systems, receptors, and enzymes. J Neurosci 5:2240-2253.

Isaac JT, Nicoll RA, Malenka RC (1995) Evidence for silent synapses: implications for the expression of LTP. Neuron 15:427-434.

Isaac JTR, Crair MC, Nicoll RA, Malenka RC (1997) Silent synapses during development of thalamocortical inputs. Neuron 18:1-20.

Itaya SK, Fortin S, Molotchnikoff S (1995) Evolution of spontaneous activity in the developing rat superior colliculus. Can J Physiol Pharmacol 73:1372-1377.

Izumi Y, Clifford DB, Zorumski CF (1992) Low concentrations of $N$-methyl-D-aspartate inhibit the induction of long-term potentiation in rat hippocampal slices. Neurosci Lett 137:245-248.

Kandler K, Katz LC, Kauer JA (1998) Focal photolysis of caged glutamate produces long-term depression of hippocampal glutamate receptors. Nat Neurosci 1:119-123.

Kirkwood A, Bear MF (1994) Homosynaptic long-term depression in the visual cortex. J Neurosci 14:3404-3412.

Kirkwood A, Lee HK, Bear MF (1995) Coregulation of long-term and experience-dependent synaptic plasticity in visual cortex by age and experience. Nature 375:328-331.

Kleinschmidt A, Bear MF, Singer W (1987) Blockade of NMDA receptors disrupts experience-dependent plasticity of kitten striate cortex Science 238:355-358.

Konnerth BU, Ballanyi K, Yaari Y (1990) Voltage sensitivity of NMDA-receptor-mediated postsynaptic currents in granule cells of rat hippocampus. J Physiol (Lond) 435:275-293.

Kullmann DM, Asztely F (1998) Extrasynaptic glutamate spillover in the hippocampus: evidence and implications. Trends Neurosci 21:8-14.

Laezza F, Doherty JJ, Dingledine R (1999) Long-term depression in hippocampal interneurons: joint requirement for pre- and postsynaptic events. Science 285:1411-1414.

Lee HK, Kameyama, K, Huganir RL, Bear MF (1998) NMDA induces long-term synaptic depression and dephosphorylation of GluR1 subunit of AMPA receptors in hippocampus. Neuron 21:1151-1162.

Liao D, Malinow R (1996) Deficiency in induction but not expression of LTP in hippocampal slices from young rats. Learn Mem 3:138-149.

Lo F-S, Mize RR (2000) Synaptic regulation of L-type $\mathrm{Ca}^{2+}$ channel activity and long-term depression during refinement of the retinocollicular pathway in developing rodent superior colliculus. J Neurosci 20:RC58 (1-6)

LoTurco JJ, Blanton MG, Kriegstein AR (1991) Initial expression and endogenous activation of NMDA channels in early neocortical development. J Neurosci 11:792-799.

Marty S, Berzaghi M, Beringer B (1997) Neurotrophins and activitydependent plasticity of cortical interneuron. Trends Neurosci 20:198-202.

McBain CJ, Freund TF, Mody I (1999) Glutamatergic synapses onto hippocampal interneurons: precision timing without lasting plasticity. Trends Neurosci 22:228-235.

Monyer H, Burnashev N, Laurie DJ, Sakmann B, Seeburg PH (1994) Developmental and regional expression in the rat brain and functiona properties of four NMDA receptors. Neuron 12:529-540.

Nase G, Weishaupt J, Stern P, Singer W, Monyer H (1999) Genetic and epigenetic regulation of NMDA receptor expression in the rat visual cortex. Eur J Neurosci 11:4320-4326.

Pouzat C, Hestrin S (1997) Developmental regulation of basket/stellate cell 224 Purkinje cell synapses in cerebellum. J Neurosci 17:9104-9112.

Quinlan EM, Philpot BD, Huganir RL, Bear MF (1999) Rapid, experience-dependent expression of synaptic NMDA receptors in visual cortex in vivo. Nat Neurosci 2:352-357. 
Rabacchi S, Bailly Y, Delhaye-Bouchaud N, Mariani J (1992) Involvement of the $N$-methyl-D-aspartate (NMDA) receptor in synapse elimination during cerebellar development. Science 256:1823-1825.

Ramoa AS, Prusky G (1997) Retinal activity regulates developmental switches in functional properties and ifenprodil sensitivity of NMDA receptors in the lateral geniculate nucleus. Dev Brain Res 101:165-175.

Reiter HO, Stryker MP (1988) Neural plasticity without postsynaptic action potentials: less active inputs become dominant when kitten visual cortical cells are pharmacologically inhibited. Proc Natl Acad Sci USA 85:3623-3627.

Renger JJ, Egles C, Liu G (2001) A developmental switch in neurotransmitter flux enhances synaptic efficacy by affecting AMPA receptor activation. Neuron 29:469-484.

Rumpel S, Hatt H, Gottmann K (1998) Silent synapses in the developing rat visual cortex: evidence for postsynaptic expression of synaptic plasticity. J Neurosci 18:8863-8874.

Rutherford LC, DeWan A, Lauer HM, Turrigiano GG (1997) Brainderived neurotrophic factor mediates the activity-dependent regulation of inhibition in neocortical cultures. J Neurosci 17:4527-2535.

Rutherford LC, Nelson SB, Turrigiano GG (1998) BDNF has opposite effects on the quantal amplitude of pyramidal neuron and interneuron excitatory synapses. Neuron 21:521-530.

Sather W, Dieudonne S, MacDonald JF, Ascher p (1992) Activation and desensitization of $N$-methyl-D-aspartate receptors in nucleated outsideout patches from mouse neurones. J Physiol (Lond) 450:643-672.

Scheetz AJ, Nairns AC, Constantine-Paton M (2000) NMDA receptor mediated control of protein synthesis at developing synapses. Nat Neurosci 3:211-216.

Schnupp AA, King A, Smith A, Thompson I (1995) NMDA-receptor antagonists disrupt the formation of the auditory space map in the mammalian superior colliculus. J Neurosci 15:1516-1531.

Shi J, Aamodt SM, Constantine-Paton M (1997) Temporal correlations between functional and molecular changes in NMDA receptors and GABA neurotransmission in the superior colliculus. J Neurosci 17:6264-6276.

Shi J, Townsend M, Constantine-Paton M (2000) Activity-dependent induction of tonic calcineurin activity mediates a rapid developmental downregulation of NMDA receptor current. Neuron 28:1-20.

Simon D, O'Leary D (1992) Development of topographic order in the mammalian retinocollicular projection. J Neurosci 12:1212-1232.

Simon DK, Prusky GT, O’Leary DDM, Constantine-Paton M (1992) NMDA receptor antagonists disrupt the formation of a mammalian neural map. Proc Natl Acad Sci USA 89:10593-10597.

Smith AL, Cordery PM, Thompson ID (1995) Manufacture and release characteristics of Elvax polymers containing glutamate receptor antagonists. J Neurosci Methods 60:211-217.

Stent GS (1973) A physiological mechanism for Hebb's postulate of learning. Proc Natl Acad Sci USA 70:997-1001.

Stocca G, Vicini S (1998) Increased contribution of NR2A subunit to synaptic NMDA receptors in developing rat cortical neurons. J Physiol (Lond) 507:13-24.

Thong IG, Dreher B (1986) The development of the corticotectal pathway in the albino rat. Dev Brain Res 25:225-238.

Turrigiano GG, Leslie KR, Desai NS, Rutherford LC, Nelson SB (1998) Activity-dependent scaling of quantal amplitude in neocortical neurons. Nature 391:892-896.

Warton SS, McCart R (1989) Synaptogenesis in the stratum griseum superficial of the rat superior colliculus. Synapse 3:136-148.

Wiesel TN, Hubel DH (1965) Comparison of the effects of unilateral and bilateral eye closure on cortical unit responses in kittens. J Neurophysiol 28:1060-1072.

Williams K, Russell SL, Shin YM, Molinoff PB (1993) Developmental switch in the expression of NMDA receptors occurs in vivo and in vitro. Neuron 10:267-278.

Wu GY, Malinow R, Cline HT (1996) Maturation of a central glutamatergic synapse. Science 274:972-976.

Yang S-N, Tang Y-G, Zucker RS (1999) Selective induction of LTP and LTD by postsynaptic $\left[\mathrm{Ca}^{2+}\right]_{\mathrm{i}}$ elevation. J Neurophysiol 81:781-787.

Zhang LI, Tao HW, Holt CE, Harris WA, Poo M (1998) A critical window for cooperation and competition among developing retinotectal synapses. Nature 395:37-44. 